\title{
LAS EXPRESIONES DE LA DERECHA EN BRASIL Y EN ESPAÑA: CONSERVADURISMO, NEOLIBERALISMO Y FASCISMO
}

The Expressions of Right in Brazil and Spain: Conservative, Neoliberalism and Fascism

\author{
Francisco Pinto da Fonseca \\ Carmen Pineda Nebot
}

Fundação Getulio Vargas FGV

Eaesp y Pontifícia Universidade Católica de São Paulo PUC/SP

franciscocpfonseca@gmail.com

carmenpinedanebot@hotmail.com

\begin{abstract}
Resumen:
El objetivo es analizar las variables que llevaron al ascenso de la (extrema) derecha en Brasil que culminaron con la elección fraudulenta de Jair Bolsonaro a la presidencia de la República en 2018. Las variables analizadas son: a) la "Operación Lava Jato", por tratarse del sector ilegal/ilegítimo del Poder Judicial que destituyó a la presidenta Dilma Rousseff y encarceló sin pruebas al ex-presidente Lula; b) los grandes medios de comunicación y los sectores de las redes sociales, por el papel ideológico que tuvieron; y c) principalmente el gran capital internacional $y$ nacional $y$ sus think thanks. $Y$ como esto sucede también en otros países, como es el caso de España, que será tratado de forma comparativa, dado que el foco del análisis es el ascenso de la derecha en Brasil.
\end{abstract}

Palabras clave:

derecha, neoliberalismo, fascismo, Brasil, España

\begin{abstract}
:
The objective is to analyze the variables that led to the rise of the (extreme) right in Brazil that culminated with the fraudulent election of Jair Bolsonaro to the presidency of the Republic in 2018. The variables analyzed are: a) "Operation Car Wash", as it is an illegal/illegitimate sector of the judiciary that removed President Dilma Rousseff from the presidency of the Republic and imprisoned former President Lula without evidence; b) the mainstream media and social media sectors, due to their ideological role; and c) mainly the major international and national
\end{abstract}


capital and their think thanks. And as this also happens in other countries, as is the case in Spain, which will be treated comparatively, since the focus of the analysis is the rise of the right in Brazil.

Keywords:

Right, Neoliberalism, Fascism, Brazil, Spain

Recibido: $13 / 09 / 2019$

Aceptado: 05/12/2019

\section{LAS MANIFESTACIONES POLIFÓNICAS DE 2013, LA DESESTABILIZACIÓN POLÍTICA DEL GOBIERNO DE DILMA ROUSSEFF Y LA ELECCIÓN FRAUDULENTA DE JAIR BOLSONARO'}

Analizar la ascensión de los grupos de ideología de derecha - abajo conceptuada en Brasil implica inventariar, aunque brevemente, el conjunto de acontecimientos que vienen parlamentario/judicial/mediático/elitista en 2016 y que finalizaron en el fraude electoral que representó la "elección" de Bolsonaro en 2018.

Las manifestaciones polifónicas, con demandas pulverizadas y muy distintas, de junio de 2013, sacudieron al país. Estas manifestaciones las inició el Movimento pelo Passe Livre (grupo de jóvenes militantes, en buena parte anarquistas), contrarios a los aumentos de los billetes del transporte colectivo. Por medio de las crecientes manifestaciones capitaneadas por ese grupo, muchos otros grupos y organizaciones en buena medida vinculados a la derecha- se fueron incorporando, habiendo producido demandas muy distintas y convirtiéndose en una polifonía.

Al final de ese proceso, tanto los grandes medios de comunicación como los grupos conservadores consiguieron hegemonizar las protestas, convirtiéndolas en una crítica a la izquierda en ese momento en el poder. En otras palabras, movimientos que se iniciaron con pautas progresistas - diminución de las tarifas de los transportes públicos y acceso al transporte como política pública democrática fueron tragadas por la "onda conservadora y la derecha", cuyo tema de la "corrupción" y las críticas al papel del Estado se superpusieron a los reales problemas del país: la desigualdad social y política.

Los acontecimientos que resultaron de ahí, desde el punto de vista de las demandas de reformas democráticas, fueron por tanto modificándose intensamente. Pero, más importante, esa coyuntura parecía apuntar a un aspecto central de la política brasileña: el agotamiento de la alianza de clases organizada bajo el lulismo. Coyunturas que pueden, a veces, revelar - normalmente de manera polifónica situaciones de cambio estructural, como fue este caso. Aunque aún no se tenga una

\footnotetext{
${ }^{1}$ Esta sección, aquí parcialmente reproducida, revisada y complementada, fue originalmente publicada en el libro titulado "O golpe de 2016: razões, atores e consequências", organizado por Luiz A. Dias y Rosemary Segurado (Editora Intermeios, 2019). El capítulo, de F. Fonseca, en el que se inspira este texto, se titula "A desestabilização política e o golpe: atores e estratégias do consórcio que golpeou a democracia em 2016".
} 
completa claridad acerca del significado de las manifestaciones de 2013 que, en rigor, continuaron por distintos motivos, revelando disputas ideológicas y consecuentemente de poder, el hecho es que el llamado "pacto de clases" instaurado por el Gobierno Lula estaba colapsado, siendo el Gobierno Dilma su expresión.

En tal pacto, bajo los mandatos de Lula, fueron incluidos los miserables y los pobres, así como sectores populares organizados, como los movimientos sociales y sindicales, pero no se enfrentaron a los privilegios de las clases medias altas y al gran Capital, incluyendo ahí a los rentistas. Ejemplos claros de esa alianza "por lo alto" son el inmovilismo ante un conjunto de reformas no realizadas, tales como, entre otras: la reforma tributaria, teniendo en cuenta el perverso e injusto modelo brasileiro que saca de los más pobres proporcionalmente más impuestos (renta) que de los más ricos, así como la no reanudación del debate acerca de los impuestos sobre las grandes fortunas. Aún más grave se vuelve ese cuadro debido a la histórica desigualdad social en el país debido: a la sangría de los intereses de la deuda interna, que favorece a cerca de veinte mil familias de rentistas, incluyendo a los grandes bancos, y que fue ampliada (la deuda) con los aumentos periódicos de los tipos de interés; la estructura agraria/agrícola, articulada en el agronegocio, cuya contribución al PIB por la vía de las exportaciones paralizó cualquier tentativa de reforma estructural del campo; al oligopolio mediático, responsable de la criminalización de los movimientos sociales, por la descalificación de las instituciones políticas y por el golpismo como forma de acción política reactivo a cualquier reforma democrático/popular: los órganos de comunicación representan justamente a las clases medias altas y al Capital. Ese oligopolio no fue combatido, al contrario, como lo demuestra la vinculación a los grandes medios de comunicación de los ministros de Comunicación de los gobiernos de Lula y Dilma; la estructura crediticia federal, fuertemente vinculada a los intereses del gran capital (por medio de los bancos estatales federales): que aunque tengan efectos positivos para el empleo y la renta, el mantenimiento de esa estructura no permitió la reversión del ciclo histórico de apropiación del Estado por las elites económicas; al sistema político privatizado, por medio de la consolidación de la "contabilidad paralela" (dinero privado oficialmente no contabilizado) y de la fragmentación partidista dirigida en buena medida a los "negocios", teniendo en cuenta la lógica de las uniones/coaliciones, en el contexto de la permanentemente postergada reforma política; la participación popular, al control social y a la transparencia como aspectos cruciales - y que obtuvieron avances -, pero no "radicalizados" hasta el punto de crear nuevas correlaciones de fuerza en la sociedad, lo que incluye la cooptación del movimiento social y sindical por los aparatos estatales; a la estructura simbólica, representada por la ideología, que siguió los patrones históricos - estéticos y sustantivos - estadounidenses, lo que implicó el mantenimiento del carácter dependiente y asociado de la producción cultural nacional y la desatención de la defensa de la lengua como elemento fundamental de la soberanía, contrariamente a la experiencia francesa, por poner un ejemplo.

La excepción parece haber sido la política exterior, ya que se buscó aproximaciones con América Latina, Oriente Medio, África y otros países fuera de la tradicional vinculación al hemisferio norte. Está claro que hubo muchos otros 
avances, testados por diversos indicadores, pero estos avances no lograron construir un país distinto en lo que respecta a cambios estructurales. En otras palabras, el modelo incremental de Lula, de pacto "de todos con todos", aunque representó un avance teniendo en cuenta el conservadurismo orientado a las "clases medias y al Capital" vigente hasta entonces - es decir, de los militares a Fernando Henrique Cardoso. Al contrario, los mayores avances se produjeron en las franjas del statu quo, sin colocar en jaque las estructuras de los grandes privilegios e iniquidades.

Dado ese contexto de demandas polifónicas, reformismo "débil" desarrollados por los gobiernos del Partido de los Trabajadores y crisis sistémicas, la derecha brasileña, articulada internacionalmente, pasó progresivamente a volverse hegemónica. Aprovechó, por tanto, las manifestaciones originalmente progresistas de 2013 para establecer un nuevo patrón ético/político cuyas bases son los valores conservadores y la derecha. Es en ese sentido que la crisis que llevó a la caída de la presidenta Dilma Rousseff fue básicamente artificial, es decir, creada con el fin específico de corroer de manera fuerte la gobernabilidad de su gobierno, con la creación de un ambiente - político/ideológico, institucional y social - de caos político y económico, de ausencia de capacidad de gobernar, de ilegitimidad y de corrupción. La narrativa que predominó, igualmente creada de forma artificial, fue agriamente dirigida a la criminalización no solo de su gobierno, como del Partido de los Trabajadores, de su principal líder (Lula), del pensamiento de la izquierda, así como de la agenda que esas fuerzas representaban.

Finalmente, hay que destacar que toda la sección destinada al Brasil se basa en las obras de Santos (2017) y Fonseca (2019), que orientan los análisis sobre el ascenso de la derecha, siendo el golpe del impeachment, como vimos, minuciosamente planeado por el gran capital internacional, por las elites nacionales y por el Departamento de Estado de los Estados Unidos. La elección de Bolsonaro se incluye, por tanto, enteramente en ese contexto.

\section{FACTORES QUE HAN LLEVADO A LA SITUACIÓN ACTUAL}

El golpe parlamentario realizado el 12 de mayo de 2016 (salida formalmente temporal de la presidenta) y el 31 de agosto del mismo año (votación del impeachment, nombre "institucional" dado para deponer a la presidenta) fue el resultado de diversos factores dirigidos a la desestabilización: política, institucional, social, informativa, ideológica y moral del Gobierno Dilma. Abajo son analizados algunos de los principales fenómenos, factores y personajes de ese proceso de golpe de la democracia y de incriminación protofascista de un gobierno (Dilma Rousseff) y de un partido político (el Partido de los Trabajadores). Los aspectos aquí examinados ocurrieron simultáneamente y sobre todo se entrecruzaron. Más aun, constituyen un cuadro complejo y multifacético de aspectos, actores y cuestiones que llevaron al golpe parlamentario de 2016, articulado por actores económicos, políticos e institucionales, tanto nacionales como internacionales:

- La elección a la Cámara de los Diputados, en 2014, de cerca de 250 diputados financiados por muchos sectores empresariales, para la defensa de los intereses del gran Capital, nacional e internacional. Sectores como el agronegocio, la seguridad privada, la medicina privada, los negocios evangélicos, entre otros, financiaron a 
candidatos claramente vinculados a esos intereses. Michel Temer (entonces vicepresidente de la República) y Eduardo Cunha, presidente de la Cámara de los Diputados - aliados desde el primer momento- fueron los articuladores nacionales de su financiación y, más importante, los receptores de los valores que serán distribuidos entre los candidatos representantes del capital que, además, fueron escogidos por su posición relativamente consensuada sobre la derogación de los derechos sociales y laborales, así como de la defensa incondicional del golpe que iba a ser dado (en 2016) y del "gobierno" a ser instituido y capitaneado por Temer.

- Sectores mayoritarios de la Cámara de los Diputados, a partir de la ascensión del diputado Eduardo Cunha como presidente de la Cámara, que ostensivamente, por medio de las llamadas "pautas bombas" y del bloqueo político de todas las iniciativas del Ejecutivo, actuó para impedir cualquier iniciativa política, económica y administrativa del Gobierno Dilma. El objetivo era claramente minar al Gobierno Dilma, erosionando totalmente su capacidad de gobernar. Este proceso ocurre con la total indulgencia del Supremo Tribunal Federal (STF) que, aunque ya conocía los extractos bancarios de Cunha en Suiza, producto de sobornos millonarios, esperó a la finalización del proceso de impeachment para quitarlo de su puesto.

- El golpismo (desestabilizador, por tanto) de los partidos políticos derrotados en las elecciones de 2014, progresivamente secundados por los pequeños y medianos partidos de centro-derecha reunidos en torno al Ilamado "Centrão", teniendo como lema el no reconocimiento de la derrota electoral. El conjunto de esos partidos parte de ellos habían participado en los gobiernos Lula y Dilma - formó una mayoría sólida no solo para ayudar a dar el golpe parlamentario do impeachment sino también para sustentar el sin número de medidas antipopulares, antisociales y antinacionales Ilevadas a cabo por el Ejecutivo liderado por Temer. Debe resaltarse el paralelismo temporal y político entre la desestabilización institucional patrocinada por el Congreso Nacional (mayoritariamente) presidido por Cunha y la desestabilización "jurídica" proveniente de la Operación Lava Jato: ambas con la indulgencia del Supremo Tribunal Federal (STF). Tal proceso venía siendo gestado y tuvo en el programa del PMDB (Partido del Movimiento Democrático Brasileño), titulado "Un puente para el futuro", su guía ideológica, así como un proyecto supuestamente "social", titulado "Travesía Social"": ambos elaborados por instituciones y think tanks neoliberales.

- La conspiración de segmentos empresariales internacionales y nacionales vinculados al rentismo y a cadenas internacionales de producción, cuyo objetivo era la fragilización del G-20 - y consecuentemente del banco y del fondo recientemente creados - y la desestructuración del Mercosul, cuya razón era la desconstrucción de la política exterior Sur/Sur. Tales cambios, entre tantos otros, implicarían el reposicionamiento de Brasil en la arena internacional, eliminando su liderazgo regional y su protagonismo mundial. El viejo orden Norte/Sur ha sido por tanto restablecido en diversos sentidos y direcciones, retornando el país a importar

\footnotetext{
2 Ver respectivamente: https://www.fundacaoulysses.org.br/wp-content/uploads/2016/11/UMAPONTE-PARA-O-FUTURO.pdf y https://complemento.veja.abril.com.br/pdf/travessia\%20social\%20\%20pmdb_livreto_pnte_para_o_futuro.pdf
} 
capitales y tecnología, ampliando su dependencia de los EUA, en el contexto mayor del G-7, en términos geopolíticos y geoeconómicos.

- La casi totalidad de los empresarios nacionales deseosos, desde siempre, de la derogación de los derechos laborales y también de los derechos sociales, con intención de establecer un "ambiente de negocios" atractivo al Capital: nacional y extranjero, cada vez más interconectados. Se trata de la agenda mínima del Capital contra los trabajadores y contra los beneficiarios de programas sociales.

- La clase media altas, compuesta por profesionales liberales, pequeños burgueses, rentistas medios y todos aquellos que no viven solo o necesariamente de salarios, que estaban descontentos con las políticas de ascensión social promovidas por los gobiernos petistas (es decir, pertenecientes al Partido de los Trabajadores). Se trata de resistencia a la percepción, aunque irreal, de la perdida de prestigio y privilegios, como el acceso a la universidad y a bienes de consumo y servicios a los pobres y en particular a los pobres negros. Además, hubo la percepción de que, con el Partido de los Trabajadores (PT), la Ilamada "clase media" tradicional fue olvidada o descuidada en favor de los pobres. Esa "clase media" aparentemente esta constituida por sectores asalariados con funciones gerenciales y de confianza del Capital y por segmentos autónomos, esto es, dueños de negocios y prestadores de servicios para el Capital o para grupos de renta alta, entre otros. Su percepción del mundo es muy difundida por los grandes medios de comunicación.

- Sectores ascendentes de las clases medias bajas - aquello que se llamó, no sin polémica, "la nueva clase media" -, cuya ascensión se dio justamente por las políticas públicas inclusivas de Lula y Dilma, fueron seducidas por el discurso ideológico de la "meritocracia individual", acercándose al conservadurismo. Tal seducción se produjo tanto por el discurso mediático como por la propagación y consolidación de las diversas iglesias evangélicas pentecostales en las periferias del país. Esas iglesias, fundamentalmente neopentecostales, propagan igualmente mensajes ideológicos de valoración del esfuerzo individual, expresan aversión al conflicto y negación a la solidaridad política, en contraposición a la solidaridad familiar y sobre todo religiosa: aspectos confluyentes con la meritocracia individual, tan del gusto de los neoliberales. También segmentos de "inocentes útiles" (trabajadores asalariados de renta baja y media), que fueron fuertemente penalizados por la política económica y antisocial de Temer y ahora de Bolsonaro, cayeron en la trampa astuta del discurso de "combate a la corrupción" - verdadera cortina de humo del golpe de 2016, intentado además en 2005 con el llamado "mensalão" - y pasaron a apoyar, aunque pasivamente, la desestabilización.

- Los grandes medios de comunicación comerciales (emisoras de tv y radios, periódicos y revistas y grandes portales de internet) que, aprovechándose de la más completa desregulación y desreglamentación del Estado brasileño en lo que respecta a la comunicación social, y recargada - curiosa y paradójicamente - por sustanciosos recursos publicitarios de los gobiernos petistas, se lanzaron a la dolorosa campaña golpista. Su actuación desestabilizadora para el golpe fue decisiva para crear y ampliar el clima y el ambiente antigubernamental y antipetista (es decir, contrario al Partido de los Trabajadores). Debe resaltarse el papel decisivo y primordial del Sistema Globo en ese proceso, aunque articulado con los otros medios. Igualmente, aunque dirigido a sectores minoritarios, tanto el mundo digital de los portales, sites, blogs como de las redes sociales (facebook y twitter) y también 
el whatsApp, fueron un campo de batalla importante entre dos segmentos opuestos: los pros y los contras al impeachment. Esos canales fueron y son utilizados para expresar: puntos de vista alternativos a los de los grandes medios de comunicación, desconstruyendo sus medias verdades, mentiras y manipulaciones; la opinión de grupos golpistas, que no solo refuerzan la narrativa de la gran prensa asociada al Poder Judicial desestabilizador como también vinculaban la inmensidad de "fake news", contribuyendo a la creación de la histeria colectiva, suministrada, se reitera, por los grandes medios de comunicación, a su vez basada en los "hechos creados" por la Operación Lava Jato/Ministerios Públicos/STF.

- La acción inconstitucional - por tanto ilegal -, selectiva, persecutoria y articulada de los grandes medios de comunicación comerciales de la Operación Lava Jato, cuyo objetivo pasó a ser fundamentalmente destruir política y electoralmente al Gobierno Dilma, al PT y a Lula. La Operación Lava Jato atenta ostensiva y enérgicamente contra el Estado de Derecho Democrático. El discurso moralista del supuesto combate a la corrupción, incentivado por el juez Sérgio Moro - cuya actuación es militantemente política y extralegal, supuso la puerta de entrada para todo tipo de oportunismo político: jurídico, político/electoral, informativo, parlamentario, social e ideológico. El Lava Jato pasó a funcionar simultáneamente como "partido político" y como "agencia de noticias políticas sesgadas" (en un claro atentado al Estado de Derecho), aunque disfrazada de "normas legales e impersonales".

- La referida indulgencia del Supremo Tribunal Federal (STF) y de la Procuradoria General de la República (PGR) a los atentados al Estado de Derecho Democrático, es decir, a la Constitución Federal, al Derecho Penal, al Código Procesal Penal, a las leyes infraconstitucionales, entre muchas otras, diseñadas por la Operación Lava Jato, esto es: la primera instancia en Curitiba, el Ministerio Público Federal y algunas secciones estaduales, la Policía Federal y el Tribunal Regional Federal-4 (TRF-4) de Porto Alegre, donde se inscribe la primera instancia de Curitiba. Luego, las instancias superiores (STF y PGR, pero también el Superior Tribunal de Justicia - STJ) estuvieron asociados a la Operación Lava Jato en un complejo continuum. También el propio Tribunal de Cuentas de la Unión (TCU) fue pieza fundamental de la conclusión del golpe al rechazar las cuentas del Gobierno Dilma por la utilización de las mediáticamente y publicitariamente tituladas - "pedaladas fiscales" (término mediático que pretendió criminalizar las prácticas contables comunes en la Administración Pública brasileña simplemente por el hecho de haber sido efectuadas por la presidenta Dilma, con el objetivo de destituirla). Tales medidas expresan la preocupación de los golpistas por "legalizar" el golpe por medio del cumplimiento de ritos, procedimientos y formas que, no obstante, tenían por base un "no objeto", esto es, el no acometimiento del delito de responsabilidad.

- Las acciones de la Policía Federal (PF), elemento de la Operación Lava Jato, con los mismos propósitos de esta, y sin que el Ministerio de Justicia - al cual está subordinada - en el Gobierno Dilma, dirigido por José Eduardo Martins Cardoso, no hiciese nada por contenerla en el sentido de circunscribir su actuación a los marcos constitucionales y republicanos. Hubo una especie de autonomía desregulada en la que delegados, investigadores y policías se sentían libres para producir indicios sin vinculación con la realidad; filtrar informaciones, muchas veces secretas; 
espectacularizar denuncias, operaciones y prisiones, en detrimento del "debido proceso legal" y del "derecho de defensa"; entre otros aspectos.

- Los think-tanks (como el Instituto Millenium), y sus financiadores internacionales (hermanos Koch, por ejemplo) y nacionales (Fundación Lemann, Federación de las Industrias del Estado de Sao Paulo, entre tantos otros), dirigidos a la propaganda ideológica que instrumentalizó - y financió - grupos de derecha como el Movimiento Brasil Livre, el Vem pra Rua y los Revoltados On Line, entre otros. Grupos empresariales igualmente participaron de esa campaña ideológica (con financiación) antipetista, anti-gobierno, anti-Lula y anti-derechos sociales/laborales/políticos/civiles. El papel de la financiación del golpe es capítulo aparte y merece más estudios sobre ello.

- El Senado, en la recta final del "proceso" - en el sentido kafkaniano - del impeachment, pasó a actuar ostensivamente de forma golpista, produciendo una verdadera pieza de ficción (supuestamente jurídica) sobre el supuesto "delito de responsabilidad" de la presidenta Dilma. La pieza acusatoria no solo no definió que el delito de la acusada, lo que se llamó de "pedaladas fiscales", no se configura como "delito de responsabilidad". Dio continuación, por tanto, a la farsa del impeachment, que había comenzado en la Cámara de los Diputados.

- La crisis económica internacional, derivada del crash de 2008 y no transformada estructuralmente hasta hoy en día, fue postergada por el Gobierno Dilma -aunque con medidas a veces por encima de lo recomendable - por medio de las Ilamadas "políticas anticiclicas". Tales políticas se agotaron, ya que tienen una validez limitada en el capitalismo. Su agotamiento contribuyó mucho al fin de la "alianza de clases" perseguida por el Gobierno Lula desde la "Carta al Pueblo Brasileño" y por el híper realismo gubernamental de los estrategas de los gobiernos petistas ${ }^{3}$. En consecuencia hundió el - tomado como mantra - "presidencialismo de coalición" sin que el gobierno y el PT consiguiesen revisar mínimamente sus estrategias ante la nueva realidad.

- Finalmente, el modelo contemporáneo de acumulación capitalista (posfordista), basado en la flexibilización del capital (combinación del capital productivo con el especulativo, con predominio de este), del consumo (obsolescencia programada, producción por lotes, just in time) - en pleno desarrollo en Brasil -, y de la fuerza de trabajo. En cuanto a esa, sus derechos fueron derogados por la "reforma" laboral de Temer. Todo eso en un contexto de profunda interconexión internacional. Se puede decir que tales transformaciones son exigencias del modelo flexible de acumulación, es decir, la reducción substantiva del "coste" del trabajo - tratado ideológicamente de "coste Brasil" - y la creación de "ambiente de negocios propicio al Capital internacional", que supuestamente implicaría la amplia llegada de capital extranjero, con supuestos "beneficios" a países que, en la división internacional del trabajo, no tendrían como "competir" por la producción tecnológica y por la exportación de productos con valor agregado, caso de Brasil: posición de hecho demostrada en los Gobiernos de Cardoso. El modelo de acumulación capitalista, encarnado por capitalistas, ideólogos, think tanks, medios de comunicación, financiadores y tantos otros es una fuerza internacional, con conexiones claras en Brasil. Los referidos

${ }^{3}$ Gobiernos del Partido de los Trabajadores. 
programas del PMDB están fuertemente relacionados a esa concepción retrógrada, antisocial, cercana al rentismo y a la perdida de la "soberanía nacional".

Esos fenómenos, factores y actores se convirtieron, por tanto, en un consorcio desestabilizador que se fue formando a lo largo de los gobiernos petistas, y que tuvo en los siguientes momentos puntos de agudización, en una especie de continuum corrosivo al Gobierno Dilma y a las reglas democráticas: en 2005, el llamado "mensalão" - terminología rápidamente adoptada y propugnada por los grandes medios de comunicación - representó la primera tentativa de desestabilización institucional, teniendo el STF un papel crucial $^{4}$; en 2012, la postura crítica del Gobierno Dilma y de la propia presidenta sobre los altos tipos de interés aplicados en Brasil por los bancos tuvo como respuesta una oposición silenciosa del rentismo; en 2013, las referidas manifestaciones polifónicas de descontento con diversas políticas públicas con progresivo predominio de los grupos neoliberales/conservadores; en 2014, distintas manifestaciones contra la Copa del Mundo de futbol en Brasil y abucheos a la presidenta en la apertura de ese evento, cuyo simbolismo es importante debido al perfil elitista de los participantes; y en 2015, masivas manifestaciones de grupos conservadores, muchos de ellos financiados, con el objetivo explícito de deponer a la presidenta Dilma del poder. Vistos en perspectiva, esos fenómenos forman una cadena articulada que, aunque con muchos actores que no necesariamente representan las mismas fracciones de clase, tuvieron unidad suficiente para derrumbar al gobierno legítimo.

Específicamente en cuanto a la escisión abierta por el rentismo, se trata posiblemente de la más importante sacudida en la gran coalición de clases articulada desde el Gobierno Lula, ya que ese capital y su cadena especulativa -entonces presente en el pacto interclases - paulatinamente se distanciaron de esa alianza, financiando y actuando en favor del golpe. Desde el punto de vista politológico, posiblemente ese fue uno de los factores detonadores del golpe, ya que se trata de articulación de fuerzas internacionales y transnacionalizadas, a su vez mancomunadas con el gobierno de los Estados Unidos. Se trata aquí de conspiración, cuyo nombre y estrategias proceden del Ilamado Plan Atlanta ${ }^{5}$.

Por lo tanto, los diversos actores presentes en ese conjunto de manifestaciones del juego internacional a los bastidores y las calles -, aunque no tuviesen previamente un centro articulador vertical, tuvieron/tienen en la Operación Lava Jato, con apoyo del STF y articulación con los grandes medios de comunicación, el aparato con capacidad de dirección que dio musculatura al golpe parlamentario

4 Según cierta línea interpretativa, se trató de una prueba de cuño jurídico/político/institucional/mediático que, al intentar la caída del presidente Lula, dio inicialmente marcha atrás para repensar tácticas y estrategias, culminando en la Operación Lava Jato. Se habría tratado, por tanto, del primer ensayo golpista que, aunque derrotado, acumuló fuerzas para, en la primera oportunidad, desbancar a los gobiernos petistas.

${ }^{5}$ Noticias importantes sobre el Plan Atlanta pueden verse en los medios de comunicación alternativos, como en el caso del siguiente reportaje entre otros: https://www.pragmatismopolitico.com.br/2017/07/plano-atlanta-golpe-judicial-midiaticoamerica-latina.html 
formal, arrinconando a los sectores progresistas en las calles y en las instituciones. En esas últimas, la sumisión de los jueces progresistas y "liberales" del STF a "jueces" militantes y retrógrados, llevó a gran parte de los jueces del "centro" a estar de acuerdo con el golpe.

- Además de esos aspectos, se deben destacar las debilidades del Gobierno Dilma, en varias dimensiones (internas del gobierno y en su relación con el Congreso Nacional y con la sociedad), y la perdida de hegemonía del Partido de los Trabajadores ante el sistema político, sindical y de los movimientos sociales. Esos aspectos, sin embargo, de ninguna forma justifican el golpe de Estado realizado en 2016.

De esa forma el golpe fue aplicado. Sus elementos simbólicos combinan proceso kafkaniano con ópera cómica, en un ambiente sin sentido y estrafalario. Por lo tanto, el pos-golpe se sustentó en una mayoría parlamentaria, en la indulgencia del Poder Judicial, en el apoyo de los grandes medios de comunicación y, más recientemente, por la interferencia militar, cuyos lados ocultos y divisiones no son enteramente conocidos.

\section{Ascensión de J. Bolsonaro a la PresidenCia de la República Brasileña}

Ese proceso de golpe ampliado, especie de Estado de Excepción Permanente (como es conceptuado por G. Agamben, 2004) creó las condiciones para la ascensión de Jair Bolsonaro, figura lúgubre, taciturna, despreciable y protofascista de la vida política brasileña.

Ex militar expulsado de las Fuerzas Armadas por insubordinación y tentativa, por insatisfacción salarial, de atentado terrorista a las propias instalaciones del Ejército se convirtió en parlamentario (diputado federal) sin ningún liderazgo, protagonismo o importancia, excepto por declaraciones en defensa de las dictaduras militares, de la tortura y de los torturadores y por ser contrario a los derechos humanos y de las minorías. En otras palabras, un verdadero protofascista.

Su base de apoyo es también polifónica: sectores fascistas; los opositores de los grupos de la izquierda, y en particular del Partido de los Trabajadores; sectores ingenuos capturados por las "fake news" financiadas con dinero ilegal (Caja 2) y coordinadas por Steve Bannon; fundamentalistas religiosos (y conservadores con base religiosa), sobre todo evangélicos neopetencostales; las clases medias altas (e incluso sectores ascendentes de las clases medias, que creen en la "meritocracia"); el gran capital nacional e internacional; las Fuerzas Armadas; y los grandes medios de comunicación.

Lo más importante, es que la base de sustentación económica de Bolsonaro proviene del gran capital: agronegocio, muchos sectores empresariales, la industria de armas, los negocios evangélicos, y sobre todo el rentismo internacional, con vinculaciones nacionales. Como se observa, los trabajadores - gran mayoría de la población - están claramente fuera de esa base de representación. Parte de los que viven del trabajo y apoyaron/apoyan a Bolsonaro son, verdaderamente, profundamente manipulados ideológicamente, ya que la amplia red de 
comunicación directa - típica del populismo de derecha, ahora high tech -, vía "redes sociales", operó fuertemente en las elecciones de 2018.

Bolsonaro fue elegido de forma fraudulenta, pues: la Operación Lava Jato/Poder Judicial creó las condiciones "acusatorias" (antes y durante las elecciones) contra el Partido de los Trabajadores, que fueron ampliamente divulgadas y vulgarizadas por los grandes medios de comunicación en el sentido de su criminalización. Particularmente el impedimento de que Lula participara en las elecciones y de que ni siquiera pudiera dar entrevistas formaba parte de ese plan; las referidas "redes sociales" crearon la "realidad virtual paralela", manipulando sectores vulnerables al discurso anti-izquierda y anti-PT (los 10 millones de votos de más para Bolsonaro provenían potencialmente de ese grupo); la financiación ilegal (como se ha aludido) confirió además de ilegalidad, ilegitimidad a las elecciones; los grandes medios de comunicación continuaron con su travesía difamatoria, selectiva y sin ningún compromiso con el periodismo; las elites, nacionales e internacionales, continuaron el proceso de conspiración por medios diversos; entre otras estrategias.

Manipuladas las elecciones, por diversos medios (entre los cuales está el supuesto navajazo sufrido por Bolsonaro), ya que la derecha no era viable electoralmente si "juega las reglas de juego" de Brasil, el objetivo del "gobierno" Bolsonaro, que más parece un "desgobierno", se dirige a la destrucción tanto del Estado de Derecho Democrático (cuya trayectoria de destrucción viene produciéndose especialmente desde 2016) como del Estado del Bienestar Social, también iniciado con Temer.

Bolsonaro es, por tanto, la continuación ridícula y despreciable de Temer, ya que el golpe del impeachment llevó a la consolidación de la derecha, profundizándose el golpe, lo que incluye la participación activa de los militares en la vida política y en el "gobierno" Bolsonaro.

El país se encuentra sitiado - con contradicciones y fisuras - por la derechas: en las instituciones y en las calles, aunque su "capital político electoral" esta ya derritiéndose de manera extremamente acelerada, al punto de que, con cerca de cuatro meses en el cargo, sea discutida abiertamente su sucesión.

A continuación veremos, desde una perspectiva analítica, el concepto de "derecha", y a continuación el panorama europeo, sobre todo español, teniendo en cuenta que las derechas y el consevadurismo es un fenómeno internacional.

\section{DeRECHA: CONCEPTO, CARACTERÍSTICAS E IMPLICACIONES ${ }^{6}$}

Teniendo como referencia teórica la amplia obra de Norberto Bobbio, fundamentalmente sus reflexiones sobre la contraposición entre derecha e izquierda (1995), el objetivo es analizar como tal contraposición es abordada por el pensamiento a la derecha, teniendo en cuenta la centralidad que ocupa en el mundo contemporáneo. Según Bobbio (1995:81): "El hombre de derecha es aquel que se

\footnotetext{
${ }^{6}$ Esta sección, aquí reelaborada, está inspirada en el artículo de Francisco Fonseca en el Portal Carta Maior (www.cartamaior.com.br), publicado el 15/04/2019, titulado "O que é ser de direita".
} 
preocupa, por encima de todo, en salvaguardar la tradición; el hombre de izquierda, al contrario, es aquel que pretende, por encima de cualquier otra cosa, liberar a sus semejantes de las cadenas impuestas a ellos por los privilegios de raza, casta, clase etc." (énfasis de los autores). De esa forma, la derecha (o derechas, como veremos abajo) articulan tradición procedente de algún lugar del pasado, normalmente combinada con elementos religiosos; visión mística del orden; interpretaciones nacionalistas; valores de comportamiento tradicionales; y programa económico que puede ligarse tanto a la intervención del Estado como al liberalismo.

A partir de Bobbio, por tanto, se pretende reflexionar sobre la derecha, lo que implica retornar a sus orígenes, ya que, durante la revolución francesa el dúo contrapuesto - derecha e izquierda -se manifiesta por primera vez como tal, habiendo traspasado siglos, manteniéndose vivo, permaneciendo actual desde aquel momento hasta hoy en día. Desde finales del siglo XVIII hasta hoy, innumerables acontecimientos los transformaron, unas veces distanciándolos aún más, otras promoviendo ciertas proximidades, manteniendo, no obstante, aspectos diferenciadores inherentes, al tratarse de polos contrapuestos.

En particular en cuanto a la "derecha", objeto de este artículo, su trayectoria se confunde con otras corrientes de pensamiento, como el "conservadurismo" (proveniente de E. Burke y otros) y el "autoritarismo" (procedente de varias cepas). Después de todo, una imagen particular de "orden" define intrínsecamente la perspectiva de la derecha: autoritario, disciplinado, asimétrico e invariablemente pro- propietarios.

En otra dirección, la dimensión del comportamiento de los individuos en la sociedad ocupa, igualmente, la agenda de los grupos de la derecha, lo que explica el énfasis en cuestiones típicamente privadas (esas, procedentes del liberalismo), tales como: la familia, la sexualidad, la religión, la estética, entre otras, paralelamente al énfasis en las instituciones estatales y en los códigos legales/morales que deberían ocuparse de ellas. Es decir, para la derecha debería haber cierta "estatización" de la vida privada, tal como es demandado por muchos autores en diversos momentos históricos. De esa forma, no es coincidencia que regímenes de derecha, en distintos momentos históricos y en distintos países, como es el caso de Bolsonaro en el Brasil de hoy, movilice temas típicamente individuales y privados como banderas políticas, confiriéndoles un carácter supuestamente "público".

Sin embargo, en términos económicos los regímenes de derecha han adoptado o presupuestos "intervencionistas", a veces keynesianos, aunque sin preocupación social (como en el caso de la dictadura militar brasileña pos-1964), o "neoliberales", como en el caso de la dictadura militar de Pinochet en Chile y de la "semidictadura" de Bolsonaro en el Brasil de hoy. Al adoptar políticas económicas neoliberales, las derechas en el poder paradójicamente, como hemos señalado, "estatizan la vida privada", pero "privatizan la vida pública", en una clara falta de sintonía teórica.

El criterio central que define a las derechas- tal vez sea más prudente pluralizar el concepto teniendo en cuenta sus diversas connotaciones - es la defensa de la propiedad privada y de la construcción ideológica del "orden" como presupuesto 
que asegura su vigencia. De ahí deriva la lógica de los "enemigos" (internos y/o externos, según Carl Schmitt), construidos históricamente: judíos en la Alemania nazi; comunistas (en la guerra fría e incluso en el Brasil de hoy!); la izquierda en general; trabajadores, sobre todos los organizados en sindicatos y partidos; los homosexuales (debido a su comportamiento considerado como "desviado/inmoral", concebidos como atentatorios de la familia burguesa); entre otros, dependiendo del período histórico y de la sociedad. De esa forma, el tema de la xenofobia a determinados grupos es una práctica típica del pensamiento de la derecha. Eso hizo del fascismo y del nazismo expresiones máximas, y extremas, de la derecha, sobre todo cuando llegaron al poder. Aunque la obra de Schmitt va más allá del carácter binario en cuanto a la relación amigo/enemigo, se trae aquí a causa de su carácter central para la comprensión de las diversas formas asumidas por el totalitarismo.

Por lo tanto, las derechas actúan sistémicamente a favor del capital y de los capitalistas por medio de la construcción figurada del "orden" (autoritario). Se opone, en efecto, con violencia verbal, estética y física a los que, real o imaginariamente, protestan contra el capitalismo y/o contra las desigualdades producidas por ese sistema. Por ello, los trabajadores son, fundamentalmente, las primeras víctimas de las políticas económicas, así como sus organizaciones (los aludidos sindicatos, partidos y otras formas de representación política) sus víctimas políticas. Según G. Agamben, ese proceso debe ser llamado de "Estado de Excepción Permanente", pues, además de eso, implica la corrosión de valores e instituciones democráticas que aseguran el Estado de Derecho Democrático. El Estado de Excepción tiene, por tanto, reducidas las garantías fundamentales, aunque mantenga la apariencia - ilusoria - de vigencia de la democracia. En el Brasil de hoy, bajo Temer y, ahora, Bolsonaro, no solamente la "reforma" laboral, la tercerización ilimitada de todas las actividades laborales, la Enmienda Constitucional 95 (congelación de gastos exclusivamente sociales), la desaparición del Ministerio de Trabajo y la tentativa de impedir las fuentes de financiación sindical, entre otras, expresan cristalinamente el papel subalterno destinado al trabajador y la postura de aniquilación (económica e incluso político/ideológica), por medios distintos, de su representación.

De esa forma, las derechas "organizan" autoritariamente la "lucha de clases": concepto que niegan vehementemente, lo que solo prueba su validez, aunque con contornos distintos de los habidos en el siglo XIX, teniendo en cuenta el déficit de legitimidad del gran capital y de sus representantes, dado que son incapaces de conquistar el "voto popular" por las reglas del juego democrático. En virtud de ello el gran capital necesita de la derecha: sea por la vía militar, sea por la vía populista, sea por ambas, como es el caso ahora de Brasil que, por medios ilegítimos/ilegales, vía "fake news" dirigidas por las redes sociales (digitales) a grupos sociales vulnerables, demuestran la incapacidad de las elites "para jugar con las reglas del juego democráticas" provenientes del liberalismo político. En otras palabras, el "juego sucio" de las derechas se vuelve fundamental para comprender la incapacidad de la derecha para obtener legitimidad, como se observa en las elecciones fraudulentas de Trump y Bolsonaro y en la votación del Brexit, siendo la figura de Steve Bannon clave para desnudar a la derecha en una perspectiva internacional. Al final, se trata 
de un manipulador digital de la derecha a escala global con efectos perniciosos en todos los lugares en los que actúa.

De ahí surge nuevamente la "estatización de la vida privada" como elemento de manipulación, forjándose consensos al crear y mantener la lógica permanente del "enemigo": en la economía, la política, los comportamientos individuales y de grupo, entre otros ámbitos. Incluso cuando la creación de determinados "enemigos" tengan la función de producir "cortinas de humo" para que temas relevantes sean introducidos y viabilizados, vinculados por ejemplo a la eliminación de derechos y a la reproducción ilimitada del capitalismo, que expresan en gran medida una visión totalitaria de la sociedad. Por eso las derechas son por encima de todo antisocialdemócratas (e incluso antiliberales desde el punto de vista de la separación entre público y privado) y sobre todo anti-socialistas, pues pretenden englobar temas y cuestiones privadas y públicas bajo la perspectiva conservadora, autoritaria y totalizante, además de defender sociedades "desiguales".

Por ese motivo trabajadores pobres, negros e indígenas que rechazan y protestan contra la explotación, mujeres que no se someten al papel subalterno que les es dado, homosexuales y otros "inadaptados" - según la percepción de las derechas componen el cuadro que articula el "orden económico" (explotación del trabajo por el capital), el "orden político" (autoritarismo y criminalización del conflicto y especialmente de los trabajadores y de los pobres) y el "orden ideológico" (movilización permanente de sectores sociales contra un "enemigo").

Ese proceso permite impulsar el concepto - fuertemente ilusorio - de "meritocracia", a ser utilizado exclusivamente por los trabajadores que, por su propio esfuerzo e individualmente, deben rechazar el conflicto que, reiteramos, es prioritariamente de clases. Deberían también someterse a las "oportunidades" generadas por la "sociedad abierta", o sea, por la economía de mercado, "libre" por tanto de la regulación/reglamentación estatal. En ese sentido, es significativo el clásico libro de Kal Popper, "La sociedad abierta y sus enemigos", como expresión sintética de las ideas de la derecha "ilustrada", especialmente en cuanto a la polarización entre los supuestos defensores de la sociedad abierta, esto es, de la democracia, y los enemigos, lo que representa la aproximación con el pensamiento de Schmitt. Igualmente son significativas las obras de innumerables ultraliberales, como Mises, Hayek y Friedman, todos "fundamentalistas del mercado" y críticos con las "democracias basadas en la regla de la mayoría", vistas potencialmente "perjudiciales" para el mercado. El ejemplo de la unión entre la derecha (y su extremo) y el ultraliberalismo, en el caso de la dictadura chilena, fue muy bien analizado por el libro y el documental de Naomi Klein, "La doctrina del choque", pues explican el modus operandi de las derechas en el siglo XX.

De esa forma, es inherente al pensamiento de la derecha el autoritarismo por medio de la imagen mística del "orden", fuertemente representada por los grandes medios de comunicación brasileña, como demostró Fonseca en su libro "O consenso forjado - a grande imprensa e a formação da agenda ultraliberal no Brasil" (Hucitec, 2005). Del mismo modo, la defensa de la propiedad privada (y de sus clases sociales correspondientes), de valores sociales que combinan tradición conservadora (de distintas matrices) con la aludida "estatización de la vida privada", así como la 
creación/persecución a enemigos - dado que los conflictos deberían ser extirpados , configuran el núcleo del pensamiento de la derecha.

Contemporáneamente Brasil ha sido escenario de la ascensión de esas vertientes, que articulan anti-izquierdismo, antipetismo (referido al Partido de los Trabajadores) y anti-intelectualismo y, por el contrario, valoran la tradición de la religión, la familia tradicional, los comportamientos preestablecidos por el "orden capitalista" y la "meritocracia" burguesa, esto es, la combinación entre conservadurismo y valores burgueses. En particular en cuanto a la meritocracia, las iglesias neopetencostales han contribuido fuertemente a la difusión de esa ideología, al estar vinculada a la "teología de la prosperidad", que combina adoctrinación religiosa con ultraliberalismo individualizante.

Por tanto, las derechas contemporáneas, aunque profundamente reactivas ante la civilización y los derechos individuales (civiles), políticos y sociales, han utilizado mucho las "modernas" tecnologías digitales para forjar supuestos consensos para la manipulación de la realidad, fundamentalmente grotesca y grosera, convirtiéndola en paralela al mundo real, constituyéndose por tanto en "realidad paralela".

En más de un sentido las derechas representan, pues, el retorno a siglos anteriores, como el XIX, al crear hordas de miserables - como fue retratado en el clásico libro de Victor Hugo en Francia -, desprotegidos de derechos: laborales, de bienestar y sociales. Para los pobres y vulnerables la "política pública" de las derechas es la violencia policial, la persecución y la opresión, especialmente de los que se quejan. Especialmente a los trabajadores organizados, y a toda forma de manifestación cultural y también de otras formas de oposición y protestas son potencialmente perseguidos por las derechas.

En cuanto a las "políticas públicas", las proposiciones de leyes que tramitan en el Congreso Nacional, enviadas por el juez/ministro Sérgio Moro - figura importante de la derecha al haber utilizado su cargo de juez para perseguir opositores, sobre todo al expresidente Lula, y despreciando integralmente la estructura jurídica brasileña -, se adecúan enteramente a ese cuadro: "blinda a las elites" y "criminaliza a los pobres", permitiendo la matanza generalizada de esos últimos por los aparatos policiales.

Hoy, en Brasil, la derecha está en el poder, pero su cuestionable "legitimidad" es cada vez menor, como resultado de varios fraudes, entre los cuales está la criminalización de la izquierda promovida por la Operación Lava Jato, y la electoral por la vía de "fake news", entre muchas otras. También las instituciones estatales fueron, a lo largo del tiempo, cooptadas y/o apropiadas por las derechas, como en el caso de la República de Weimar en la Alemania del pre-nazismo, que preparó el terreno a la extrema-derecha, así como en el Brasil de hoy que, a partir del golpe de Estado del impeachment a la presidenta Dilma, en 2016, vio como las instituciones estatales de Justicia contribuyeron plenamente a la farsa del juicio por crimen de responsabilidad de la presidenta electa por el voto legítimo. En otras palabras, es una práctica recurrente de las derechas los golpes de Estado, en sentido estricto, por la vía militar, o por formas más sutiles, como el impeachment (golpe parlamentario) y la apropiación de las instituciones. Y en los últimos tiempos por la manipulación digital 
de la comunicación directa con los individuos: fraude y populismo por la vía de la "manipulación directa".

El discurso y la narrativa de las derechas intentan permanentemente desconstruir la sociedad basada en derechos, en el seno del Estado de Derecho Democrático. Para alcanzar tal propósito, jamás históricamente tuvo pudor en atentar, de forma violenta y/o sutil, contra: los derechos humanos (concepto que sus activistas desprecian), contra la democracia política y social (que rechazan), contra la mayoría compuesta por trabajadores (que pretenden explotar y oprimir) y contra las diversas minorías vulnerables (fundamentalmente mujeres, negros, indígenas y homosexuales, según los países), que son consideradas "desviadas" respecto a la sociedad supuestamente "homogénea y dócil" desde el punto de vista del comportamiento y del poder.

Al final, promover activamente retrocesos civiles y civilizatorios, destruir el Estado de Derecho Democrático y el Estado de Bienestar Social - conceptos que estaban en proceso de consolidación en Brasil - pertenecen al repertorio de objetivos históricos y doctrinarios de las derechas. Para ello, figuras innobles como Bolsonaro son fantoches en las manos de las elites conservadoras, ultraliberales (para los pobres) y sobre todo "rentistas". No tienen límites a la destrucción, real y simbólica, pues expresan la imagen de las "tinieblas" (procedente del imaginario religioso que tanto predican!).

Conceptuar y comprender el significado de las derechas y su modo de operar es fundamental para desnudar un movimiento que se articula internacionalmente y con pretensiones hegemónicas, como se puede ver abajo por medio de la comparación con el caso español

\section{EL CONTEXTO INTERNACIONAL: EL CASO DE ESPAÑA}

Lo primero que debemos señalar es que el caso de España se aborda como una comparación de la situación brasileña, eje fundamental de este trabajo.

España a diferencia de otros países europeos que hace años que tenían partidos políticos de extrema derecha que conseguían representación parlamentaria, como es el caso de Francia, Alemania, Holanda, etc.,., no los tenía $Y$ eso que, en los últimos años, reunía muchas de las condiciones que los favorecen: una fuerte crisis económica, un aumento de la desigualdad, desconfianza de los políticos, una oleada de casos de corrupción y un buen número de inmigrantes tanto legales como ilegales (Antón-Mellón y Hernández-Carr, 2016; Lerin, 2019). Todo ello llevaba a que España "debiera" tener un partido de extrema derecha con éxito. Pero no fue así, hasta 2018.

Antes de esta fecha solo había habido, desde la transición democrática, un partido de extrema derecha tradicional ${ }^{7}$, Fuerza Nueva, que hubiera conseguido votos

\footnotetext{
${ }^{7}$ Autores como Mudde (2007) o Ignazi (2003) distinguen dos claras familias de partidos: "la vieja extrema derecha" vinculada al fascismo y "la nueva extrema derecha" no emparentada al fascismo clásico. Está categorización es utilizada por la mayoría de politólogos que investigan el fenómeno (Antón Mellón, et.al. 2011; Hernández-Carr, 2011).
} 
suficientes para conseguir un escaño en el Congreso de los Diputados. Fue en las primeras elecciones democráticas, las de 1979, cuando Blas Piñar, su líder, consiguió obtener un escaño por la circunscripción de Madrid con una coalición, obteniendo el $2,11 \%$ de los votos. A partir de ese momento el voto de extrema derecha se reparte entre pequeños grupúsculos de Falange Española y otros grupos similares, aunque la mayoría se refugia en Alianza Popular (AP) y posteriormente en el Partido Popular (PP).

A finales de 2013 un pequeño grupo de cargos y afiliados del PP críticos con las políticas seguidas por su líder, Mariano Rajoy, crean un nuevo partido, Vox. Teniendo en ese primer momento como objetivo básico: "recoger el voto de la derecha desencantada con las políticas del PP". En enero de 2014 se presentan ante los medios de comunicación, con Santiago Abascal como secretario general y Alejo Vidal- Quadras (máximo dirigente del PP en Cataluña) como presidente de honor y cabeza de lista a las elecciones europeas.

En dichas elecciones europeas quedó en undécima posición, con 246833 votos (un 1,57\% del total), a unos 1500 votos de conseguir un escaño. En las siguientes elecciones, de 2015, al Parlamento de Andalucía solo consiguieron un 0,45\%, es decir que tampoco consiguen representación. Tampoco tienen éxito en las siguientes elecciones autonómicas y municipales. Su participación, en 2017, en una cumbre de derecha euroescéptica, en la que Abascal mantuvo contactos con líderes de la extrema derecha europea como Marine Le Pen (FN); Frauke Petry (AfD) o Geert Wilders (PVV) y el proceso soberanista de Cataluña les permite comenzar a tener visibilidad. Pero es en las elecciones andaluzas de 2018 cuando la situación da un giro, al conseguir en ellas 12 escaños y cerca del $11 \%$ de los votos, obteniendo sus mejores resultados en los municipios con una mayor inmigración (El Ejido) y en los de renta media y alta. Con su voto consiguió que no gobernara el partido ganador, Partido Socialista Obrero Español (PSOE), que llevaba gobernando la comunidad cuarenta años, algo similar ha ocurrido en otras comunidades, como Murcia o Madrid, después de las elecciones de mayo de 2019.

Su llegada al espacio electoral se ha producido por la confluencia de cuatro factores: el primero ha sido el hecho de ejercer la acusación popular del proceso secesionista en el Tribunal Supremo, al conferirle visibilidad y permitirle erigirse en una alternativa antiseparatista "dura" ante un PP a sus ojos fracasado. Un segundo factor ha sido la controversia generada por la exhumación del cadáver de Franco del Valle de los Caídos (recordamos que Cs y PP optaron para abstenerse al respecto al Congreso). Lo que ha puesto en primer plano a la "ley de la memoria histórica", ley que la derecha siempre ha rechazado. Un tercer elemento ha sido la recomposición de un PP dividido y castigado por la corrupción. Finalmente, hay que incluir la rivalidad de PP y Cs por el voto de derecha, que los ha llevado a dar peso a la inmigración en la agenda política, lo que ha beneficiado a Vox.

Aunque en opinión de Sánchez - Cuenca (2018) el factor más determinante es la crisis constitucional que atraviesa España desde la crisis catalana de otoño de 2017, que ha activado el lado más excluyente e intolerante del nacionalismo español. Hasta dicha crisis el nacionalismo español (que nunca ha dejado de existir) se basaba en valores cívicos, era compatible con un cierto cosmopolitismo europeísta y 
tenía su base en la Transición y, más específicamente, en la Constitución de 1978. Otros autores (Betz, 2004; Rydgren, 2007; Mudde, 2007) también consideran al nacionalismo como factor decisivo aunque calificando su posición no de nacionalista sino de ultranacionalista.

En su mensaje Vox ha incluido elementos identificados como antifeministas e islamófobos, haciendo también hincapié en la reivindicación de valores tradicionales como la cazay la tauromaquia, en el nacionalismo centralista, el rechazo al aborto y en propuestas económicas de signo liberal, en contraste en este último aspecto con las posiciones más estatistas de partidos nórdicos de extrema derecha como los Verdaderos Finlandeses o el Partido Popular Danés. Su discurso incorporaría todos los elementos ideológicos que caracterizan a un partido de extrema derecha radical o derecha radical populista: nacionalismo, reacción al cambio cultural, nativismo y autoritarismo (Casals, 2003; Mudde,

2007; Antón-Mellón, 2007); así, sus propuestas en la dimensión cultural, relativas a la inmigración, la seguridad o la ilegalización de partidos, asociaciones y ONG que busquen acabar con la unidad de España, son adscritas a esta posición del espectro político. Según Steven Forti (2018), el recetario de propuestas de Vox está tamizado por una gruesa capa de ultranacionalismo español de matriz nacionalcatólica autoritaria, que se plasmaría en sus reivindicaciones territoriales en relación a Gibraltar, de la reivindicación de la dictadura franquista, de la mano dura contra el independentismo catalán, de la derogación de la Ley de Memoria Histórica y de la centralización del Estado y liquidación de la autonomía de las regiones. También es identificado como nacional-católico por Louie Dean Valencia-García (2018). Según Casals (2019), dicho ultranacionalismo vertebrador del ideario del partido es identificado por parte de este con una "visión biológica y palingenética de la patria", la "España viva", y con una cultura de inspiración católica. Además ha sido descrito alternativamente como "nacionalista y neoliberal", rigurosamente opuesto al aborto y con una política moral muy restrictiva (Hennig y Meyer-Resende, 2016), como "ultraconservador" (Labio, Labio y Pineda, 2016) y como un amago de intento de dotar de base social amplia a la ultraderecha mediante un desplazamiento posfascista (Gil-Benumeya, 2018).

En lo que respecta a la financiación, según fuentes de Vox lo hace a través de las cuotas de sus afiliados y donaciones, apreciándose que desde su nacimiento ha recibido dos millones de euros. Sin embargo, según el diario El País el partido fue fundado gracias a la aportación de un millón de euros por parte de la organización de exiliadosiraníes, el Consejo Nacional de Resistencia Iraní(CNRI), de inspiración anticapitalista y contrario al actual gobierno de la República Islámica de Irán y que formó parte de la lista de grupos terroristas internacionales (Gil, 2018). También reciben ayudas de think thanks internacionales y mantienen contactos con miembros y ex miembros del gobierno Trump, como es el caso de Steve Bannon que se ha reunido varias veces con ellos y que los ha definido como "un partido basado en la soberanía y la identidad del pueblo español" ${ }^{\prime 8}$. Habiendo adoptado elementos

${ }^{8}$ Algo que como hemos visto anteriormente comparte con la derecha brasileña. 
del trumpismo, como la consigna "Hacer España grande otra vez", la necesidad de un uso masivo de armas para defenderse y el buscar un leitmotiv político en la construcción de un muro fronterizo a Ceuta y Melilla. Vox, por tanto, se ubica a caballo del pasado y del presente, posicionamiento que le homologa a la derecha populista europea mientras preserva rasgos propios.

Siguiendo también a los dos "referentes" de la extrema derecha populista, Trump y Bolsonaro, ellos tampoco confían en los medios de comunicación, aunque si participan en ellos y usan masivamente las redes sociales. Sus resultados en las elecciones generales celebradas el 28 de abril no han sido las que esperaban (24 escaños), pero parece que España ya ha entrado en la ola populista de extrema derecha que barre el mundo.

\section{A MODO DE CONCLUSIÓN}

El proceso político brasileño se ha transformado, de forma abrupta, a la derecha, desde 2016, aunque desde 2013 la polifonía de las protestas sociales ha traído a la luz a las más variadas derechas al proyecto de la movilización política.

El golpe parlamentario del impeachment en 2016, basado en la Operación Lava Jato y en los grandes medios de comunicación y debidamente financiado internacionalmente, representa los intereses rentistas del gran capital, paralalelamente al papel golpeador de los EUA. Bolsonaro es apenas la expresión estrafalaria de ese "golpe permanente", cuya "excepción político/jurídico" es la regla, en el caso del "fraude electoral" que hizo posible su ascensión a la presidencia de la República.

Pero, como vimos el crecimiento de las derechas es un fenómeno internacional, como se observa en Europa y, ahora, en España. Por tanto fue necesario, en este artículo, analizar el concepto y las características de la "derecha", como forma de comprender su modus operandi.

Debe observarse que el movimiento internacional de derecha no es espontaneo y mucho menos proveniente de los grupos populares. Al contrario, se trata de una articulación empresarial conservadora, fundamentada en asociaciones empresariales, think tanks ultraliberales, capitalistas billonarios (caso, por ejemplo, de los hermanos Koch), partidos políticos liberal/conservadores, parte significativa de los grandes medios de comunicación (revista The Economist al frente), entre otros grupos que funcionan como aparatos privados de hegemonía, según la clásica definición de Antonio Gramsci. Por tanto, se trata de la lucha político/ideológica sobre los destinos de las sociedades, de la democracia política y social y del "conflicto distributivo" en perspectiva simultáneamente nacional (a los diversos países) e internacional. En ese sentido, se puede afirmar que las distintas derechas, fundamentalmente las más vinculadas al neoliberalismo, pretenden corroer la democracia, tanto política como social, aproximándose al fascismo.

De esa forma, esperamos contribuir a desnudar a la derecha y también a conseguir una "sociedad civilizada" y anclada en el Estado de Derecho Democrático y en el Estado del Bienestar. 


\section{BiBLiografía}

AGAMBEN, Giorgio. (2004). Estado de exceção. São Paulo: Boitempo.

ANTÓN-MELLÓN, Joan. (2007). "La cultura e ideología política del neopopulismo en Europaoccidental: MNR/FN (Francia), FPÖ (Austria) y Lega Nord (Italia)", en SIMÓN, Miguel Angel. (ed.), La extrema derecha en Europa desde 1945 a nuestros días, Madrid: Tecnos.

ANTÓN- MELLÓN, Joan., CABEZAS DE ALCALÁ, Silvia., LARA AMAT y LEÓN, Joan., \& VELILLA, Javier. (2011). "Inmigración y discurso electoral en las elecciones municipales de 2007 en Cataluña. Análisis de la similitud y divergencia en relación al discurso xenófobo de la derecha radical europea neopopulista". Crítica Penal y Poder 1. Pp. 69-87.

ANTÓN- MELLÓN, Joan y HERNÁNDEZ-CARR, Aitor. (2016). "El crecimiento electoral de la derecha radical populista en Europa: parámetros ideológicos y motivaciones sociales". Política y Sociedad 53 (1). Pp. 17-28.

BETZ, Hans-Georg. (2004). La droite populiste en Europe: extrême et démocrate. Paris: Autrement.

BOBBIO, Norberto (1995). Direita e Esquerda - razões e significados de uma distinção política.

BURKE, Edmund (1961). Reflections on the revolution in France. New York, Delphin Books, Doubleday \& Co.

CASALS, Xavier. (2003). Ultrapatriotas. Extrema derecha y nacionalismo de la guerra fría a la era de la globalización. Barcelona: Crítica. São Paulo, Editora da Unesp.

CASALS, Xavier. (2009). La Plataforma per Catalunya: la eclosión de un nacionalpopulismo catalán (2003-2009). Barcelona: ICPS.

DARDOT, Pierre y LAVAL, Christian. (2016). A nova razão do mundo - ensaio sobre a sociedade neoliberal. São Paulo: Boitempo.

FALCÃO, Joaquim. ; ARGUELHES, Diego Werneck. y RECONDO, Felipe. (orgs). (2017). Onze Supremos - o Supremo em 2016. Rio de Janeiro: FGV.

FONSECA, Francisco (2005). O consenso forjado. A grande imprensa e a formação da agenda ultraliberal no Brasil. São Paulo: Hucitec.

FONSECA, Francisco (2019). "A desestabilização política e o golpe: atores e estratégias do consórcio que golpeou a democracia em 2016", en DIAS, Luiz A. y SEGURADO, Rosemary (orgs.), O golpe de 2016: razões, atores e consequências", São Paulo: Editora Intermeios.

FONSECA, Francisco (2019). "O que é ser de direita". Portal Carta Maior www.cartamaior.com.br, publicado el 15/04/2019

FORTI, Steven. (2018). "Il boom di Vox: chi è e cosa pensa l'estrema destra spagnola". Consultado el 3 de diciembre de 2018. . MicroMega.

GIL, Joaquín. (2018). "Descenso a las cuentas de Vox". Consultado el 20 de diciembre de 2018, El País, en http://elpais.com 
GIL-BENUMEYA FLORES, Daniel (2018). “Viejas políticas y nuevos racismos. La izquierda frente a la islamofobia". Revista de Estudios Internacionales Mediterráneos (Universidad Autónoma de Madrid) 24. pp. 49-70. ISSN 1887-4460. doi:10.15366/reim2018.24.004.

GONÇALVES, Míriam. (org.). (2018). Enciclopédia do golpe - o papel da mídia. Bauru: Canal 6 Editora.

HENNIG, Anja y MEYER-RESENDE, Madalena. (2016). "Bedingungen der Aktivierung von moralpolitischen Konflikten", en WERKNER, Ines-Jacqueline y HIDALGO, Oliver (Eds.). Vox ist zwar vor allem nationalistisch und neo-liberal, lehnt aber Abtreibung rigoros ab Springer. pp. 304-305. ISBN 978-3-658-117924. doi:10.1007/978-3-658-11793-1.

HERNÁNDEZ-CARR, Aitor. (2011). "La derecha radical populista en Europa: discurso, electorado y explicaciones". Revista Española de Investigaciones Sociológicas, 136 (1) . pp.141-159.

IGNAZI, Piero. (2003). Extreme right parties in Western Europe. Oxford: Oxford University Press

LABIO, Bernal; LABIO, Aurora y PINEDA, Antonio. (2016). "Leftward Shift, Media Change? Ideology and Politics in Spanish Online-Only Newspapers After the 15-M Movement". International Journal of Communication 10. pp. 2661-2682. doi:19328036/20160005

LERÍN IBARRA, David. (2019). "La nueva derecha radical como reto a la gobernanza y a la calidad de la democracia". Cuadernos de Gobierno y Administración Pública 6 (2). Pp. 93-116.

MUDDE, Cas. (2007). Populist radical right parties in Europe. Cambridge: University Press

Cambridge.

POPPER, Karl. A sociedade aberta e seus inimigos (1974). Belo Horizonte, Itatiaia.

PRONER, Carol; CITTADINO, Gisele; RICOBOM, Gisele y DORNELLES, João (orgs.). (2017). Comentários a uma sentença anunciada - o processo Lula. Bauru: Canal 6.

RABELO, Renato y MONTEIRO, Adalberto. (orgs.). (2017). Governos Lula e Dilma: o ciclo golpeado (contexto internacional, realizações, lições e perspectivas). São Paulo: Anita Garibaldi.

RYDGREN, Jens. (2007). "The sociology of the radical right". Annual Review of Sociology 33, pp. 241-262.

SÁNCHEZ - CUENCA, Ignacio. (2018). "Vox y nacionalismo español". Consultado el 5 de diciembre de 2018, Infolibre.

SANTOS, Wanderley Guilherme dos (2017). A democracia impedida - o Brasil no século XXI. Rio de Janeiro: FGV.

SCHMITT, Carl (2015). O Conceito do Político. Edições 70: Lisboa. 
SERRANO, Pedro Estevam. (2015). A justiça na sociedade do espetáculo. São Paulo: Alameda Editorial.

SERRANO, Pedro Estevam. (2016). Autoritarismo e golpes na América Latina: breve ensaio sobre jurisdição e exceção. São Paulo: Alameda.

VALENCIA-GARCÍA, Louie Dean. (2018). "Vox and the return of the radical right in Spain". Centre for Analysis of the Radical Right. Consultado el 7 de diciembre de 2018.

VALIM, Rafael. (2017). Estado de Exceção: a forma jurídica do neoliberalismo. São Paulo: Contracorrente. 